\title{
PROGRESSIVE MATRICES AND SCHOOL SUCCESS: A FACTOR ANALYTICAL STUDY
}

\author{
S. C. Dash Radhanath Training College, Cuttack 1 \\ R. Kanungo Ravenshaw College, Cuttack, India.
}

One of of the pressing needs of India today is to devise tests suitable to her cultural conditions for proper vocational and educational selection and guidance. Simply devising tests would be of no avail unless through research, we try to objectively determine what abilities these tests are really finding out. Then only they can have some predictive values. For this purpose, the existing non-verbal culture free tests like Raven's Progressive Matrices can be used and their predictive values for determining scholastic abilities of individual students in our educational system can be found out.

We find that a numder of subjects requiring the exercise of different abilities are being taught at the school level, and also the methods of teaching, examination, and evaluation in a particular State have their own peculiarities determining the factors in scholastic abilities. So after determiniag what ability a test is likely to show, we are further in need of finding out how far the test is able to predict the success of students in different subjects. In an earlier study it was found out that, "Literary aptitude plays its most important part in the language paper. Its correlations with History and Science are moderate, and it is interesting that they are equal. But its correlation with Mathematics is the lowest."1) Similarly it is possible to find out the influence of the non-verbal intelligence or the ability for clear thinking and observation on the proficiency on various school subjects. Again how far the Progressive Matrices test which is most saturated with ' $\mathrm{g}$ ' is able to measure the overall educational proficiency of students in our system of school education has to be seen.

It has been pointed out that psychological tests and school examination marks often measure different things. ${ }^{\text {) }}$ Hence students showing higher innate intelligence may not prove high educational attainment in school examinations. As a matter of fact our system of education at least at the secondary level encourages cramming. Memorization, mostly of rote type leads to success in some of the subjects. Therefore, for the purpose of differential diagnosis, that is to predict the success and failure of the pupils in different school subjects by means of different tests, we have to look into the presence of various factors running through the tests as well as school courses.

\section{PROBLEM}

The present study makes an attempt (i) to see how far intelligence as measured by Raven's Progressive Matrices (1938) correlates with success in some of the important subjects of the school curriculum aud the overall success in the class examination: and (ii) to obtain the meaningful factors running through these school subjects by analyzing the examination marks of students.

1. The ordar of presentation of names of the au thors is strictly alphabetical. 


\section{METHOD}

Sample:- 100 students, 74 boys and 26 girls of the top matriculation class of Ranihat High School, Cuttack, ranging in age from 13 to 17 years served as a sample in this investigation.

Procedure:-

Raven's Progressive Matrices (1938) was applied to 100 students. Their scores on this test can be considered as measure of their non-verbal intelligence (2). Mathematics (M), regional language (L), History $(H)$, General Science (S), General Knowledge (Gk) were taken as representative of the school subjects. The marks obtained by the same group of students in each of the subjects in three successive examinations were taken in to consideration and the average marks in each subject for each student was calculated. The average of the Aggregate (Ag) marks in those three school examinations for each student was also calculated, showing roughly the degree of overall success in examination for a student.

The Progressive Matrices $(\mathrm{Mt})$ scores were correlated with the average marks in different subjects and with the average Aggregate marks. Further the average marks in each subject and the average Aggregate marks were intercorrelated. The matrix of intercorrelation for the test scores and different average marks was then factor-analyzed following the Centroid method (4). To obtain accurate estimate ef communalities, the extraction process was eterated four times.

\section{RESULTS}

The intercorrelation of Progressive Matrices scores and average examination marks of 5 school subjects and the Aggregate are presented in Table 1.

Table 1

\begin{tabular}{c|ccccccc}
\hline & $\mathrm{Mt}$ & $\mathrm{M}$ & $\mathrm{L}$ & $\mathrm{H}$ & $\mathrm{S}$ & $\mathrm{Gk}$ & $\mathrm{Ag}$ \\
\hline $\mathrm{Mt}$ & $(.38)$ & .39 & .25 & .10 & .33 & .20 & .37 \\
$\mathrm{M}$ & & $(.77)$ & .60 & .59 & .75 & .61 & .88 \\
$\mathrm{~L}$ & & & $(.56)$ & .59 & .62 & .58 & .76 \\
$\mathrm{H}$ & & & & $(.97)$ & .65 & .61 & .74 \\
$\mathrm{~S}$ & & & & & $(.73)$ & .64 & .83 \\
$\mathrm{Gk}$ & & & & & & $(.58)$ & .70 \\
$\mathrm{Ag}$ & & & & & & & $(.98)$ \\
\hline
\end{tabular}

After calculating the first factor loading, the product were subtracted from the correlations, and Table 2 shows the first residual matrix.

Table 2

\begin{tabular}{c|rrrrrrrl}
\hline & $\mathrm{Mt}$ & $\mathrm{M}$ & $\mathrm{L}$ & $\mathrm{H}$ & $\mathrm{S}$ & $\mathrm{Gk}$ & $\mathrm{Ag}$ & \\
\hline $\mathrm{Mt}$ & .20 & .07 & -.03 & -.20 & .01 & -.08 & 00 & \\
$\mathrm{M}$ & .07 & .10 & -.04 & -.10 & .02 & -.02 & .04 & \\
$\mathrm{~L}$ & -.03 & -.04 & .04 & 00 & -.01 & .04 & .03 & \\
$\mathrm{H}$ & -.20 & -.10 & 00 & .20 & -.03 & .02 & -.05 & \\
$\mathrm{~S}$ & .01 & .02 & -.01 & -.03 & .03 & .02 & -.01 & \\
$\mathrm{Gk}$ & -.08 & -.02 & .04 & .02 & .02 & .08 & -.02 & \\
$\mathrm{Ag}$ & 00 & .04 & .03 & -.05 & -.01 & -.02 & .05 & \\
\hline & .37 & .27 & .03 & .60 & .09 & .04 & .14 & $=1.54$ \\
\hline
\end{tabular}

$$
\sqrt{\mathbf{T}}=1.241 ; \sqrt{\frac{1}{\mathrm{~T}}}=.8058
$$

Changing the signs of $\mathrm{Mt}, \mathrm{M}, \mathrm{S}$, and $\mathrm{Ag}$ and replacing the diagonals by the highest values a second centroid factor was extracted and the residues are presented in Table 3. 
Table 3

\begin{tabular}{|c|c|c|c|c|c|c|c|c|}
\hline & $\mathrm{Mt}$ & $M$ & $L$ & $\mathrm{H}$ & $S$ & Gk & $\mathrm{Ag}$ & \\
\hline $\mathrm{Mt}$ & .09 & .01 & -.04 & .06 & -.01 & -.09 & -.03 & \\
\hline $\mathbf{M}$ & .01 & .05 & -.05 & -.01 & 00 & -.03 & .02 & \\
\hline L & -.04 & -.05 & .05 & -.01 & -.01 & .04 & .03 & \\
\hline $\mathrm{H}$ & .06 & -.01 & -.01 & .06 & -.01 & 00 & 00 & \\
\hline$S$ & -.01 & 00 & -.01 & -.01 & .02 & .02 & -.02 & \\
\hline Gk & -.09 & -.03 & .04 & 00 &.- .02 & .09 & -.02 & \\
\hline \multirow[t]{2}{*}{$\mathrm{Ag}$} & -.03 & .02 & .03 & 00 & -.02 & -.02 & .03 & \\
\hline & .33 & -.01 & .09 & .09 & .01 & .19 & .07 & $=.77$ \\
\hline
\end{tabular}

The signs of L,S,Gk, and Ag were changed and another factor was extracted. The extraction process was stopped thereafter, as the product of the two highest loadings falls below $\frac{1}{\sqrt{N}}$, where $N=$ number of cases. ${ }^{4}$ The unrotated factor loadings are given in Table 4 .

These show that the 2 nd and the 3 rd factor are bipolars as there are some negative signs. But these negative factors are meaningless in the present context, as the loadings indicate the extent to which different abilities enter into the performance of the individual in different subjects. Negative loadings have meaning only when we measure social and personality traits, but they are quite meaningless so far as intelligence and achievement tests are concerned.

Thus to obtain meaningful factors, the factors were rotated. Loadings taken two at a time were plotted on a graph paper. Axes were rotated so as to include all the points representing the loadings in the positive quadrant. In case of the first two loadings the axes were rotated through an angle of $38^{\circ}$ and the rotated loadings are shown in Table 5.

The rotated 1 st factor loadings and the unrotated 3rd factor loadings were then plotted on the graph paper. The axes were rotated so as to pass through $\mathrm{Mt}$, as it was assumed that the correlation of $\mathrm{Mt}$ with other subjects was due to the only factor non-verbal inteligence. The angle of rotation was $38^{\circ}$ and all the points representing the loadings were again in the positive quadrant. The final rotated values are presented in Table 6 .

Table 4

\begin{tabular}{c|rrr}
\hline & $F_{1}$ & \multicolumn{1}{c}{$F_{2}$} & \multicolumn{1}{c}{$F_{3}$} \\
\hline $\mathrm{Mt}$ & .378 & -.298 & -.376 \\
$\mathrm{M}$ & .853 & -.218 & .001 \\
$\mathrm{~L}$ & .741 & .024 & -.103 \\
$\mathrm{H}$ & .802 & .483 & .103 \\
$\mathrm{~S}$ & .851 & -.073 & .011 \\
$\mathrm{Gk}$ & .733 & .032 & -.217 \\
$\mathrm{Ag}$ & .984 & -.113 & .080 \\
\hline
\end{tabular}

\section{Discussion}

In the table of intercorrelation (Table 1) it is seen that non-verbal intelligence or the ability to observe and think clearly as indicated by $\mathrm{Mt}$ scores will have more relation with $\mathrm{M}, \mathrm{Ag}$, and $\mathrm{S}$ than with $\mathrm{L}, \mathrm{Gk}$, and $\mathrm{H}$. Its correlation with $\mathrm{M}$ is highest (.39) and with $\mathrm{H}$ is lowest (.10). Thus for overall success in examination and success in $M$ and $S$, non-verbal intelligence plays an important role, whereas $H$ requires very little of such ability.

Further $M$ has high correlation with $S(.75)$. Also Ag is very highly correlated with $M$ and $S$ (.88 and .83 respectively) than any other subject. This suggests like the popular belief that 
Table 5

\begin{tabular}{c:cl}
\hline & $\mathrm{F}_{1}^{\prime}$ & $\mathrm{F}_{2}^{\prime}$ \\
\hline $\mathrm{Mt}$ & .482 & 000 \\
$\mathrm{M}$ & .809 & .361 \\
$\mathrm{~L}$ & .567 & .648 \\
$\mathrm{H}$ & .330 & .876 \\
$\mathrm{~S}$ & .713 & .470 \\
$\mathrm{Gk}$ & .556 & .480 \\
$\mathrm{Ag}$ & .843 & .521 \\
\hline
\end{tabular}

Table 6

\begin{tabular}{c|lll}
\hline & $\mathrm{F}_{1}^{\prime}$ & $\mathrm{F}_{2}^{\prime}$ & $\mathrm{F}^{\prime} \mathrm{E}$ \\
\hline $\mathrm{Mt}$ & .611 & .000 & .001 \\
$\mathrm{M}$ & .631 & .361 & .507 \\
$\mathrm{~L}$ & .510 & .648 & .228 \\
$\mathrm{H}$ & .197 & .876 & .285 \\
$\mathrm{~S}$ & .555 & .470 & .430 \\
$\mathrm{Gk}$ & .572 & .480 & .172 \\
$\mathrm{Ag}$ & .615 & .521 & .582 \\
\hline
\end{tabular}

a student good at $\mathrm{M}$ will also be good in $\mathrm{S}$, and a student good in both stands a better chance of overall success in examination.

Other intercorrelations between various marks of different subjects are also rather very high. To interpret all these intercorrelations the final result of factor-analysis, i.e., the rotated factor loadings (Table 6) on all the subjects and the test may be seen.

The first factor runs through all the subjects with high loadings on $\mathrm{M}, \mathrm{Mt}$, and $\mathrm{Ag}$ and its lowest loading on $\mathrm{H}$. As this is the only factor running through $\mathrm{Mt}$, it has been assumed that this factor is non-verbal intelligence. It has also high loadings on $\mathrm{Gk}, \mathrm{S}$, and $\mathrm{L}$. The first factor loadings lend support to the contention that non-verbal intelligence is a necessity for $M$, but it has very little relation with the success in $H$. This also suggests that the common belief that $\mathrm{M}$ and $\mathrm{S}$ mainly require understanding of relations of relatively abstract nature, whereas success in $\mathrm{H}$ primarily depends upon cramming of factual contents, may have a grain of truth. This contention finds support in a parallel study ${ }^{1}$ ) where it was found out that the general intelligence or the ' $\mathrm{g}$ ' factor had the highest loading on $\mathrm{M}$ and the lowest loading on $H$. Non-verbal intelligence is only one aspect of this ' $\mathrm{g}$ '. It has been suggested by Raven ${ }^{2}$ ) that verbal or langunge test should also be used along with Progressive Matrices to measure general intelligence.

By looking at the third rotated factor (Table 6) we get a picture where again loadings of this factor are high on $\mathrm{M}, \mathrm{Ag}$, and $\mathrm{S}$. It is quite reasonable to presume that such a factor must be verbal intelligence including verbal comprehension and verbal reasoning. Low loadings of this factor on $\mathrm{H}, \mathrm{L}$, and $\mathrm{Gk}$ suggest that success in these subjects do not require much of verbal intelligence in our system of education. A broad ' $\mathrm{g}$ ' factor, however, includes both verbal and non-verbal intelligence and both of them influence overall school success and success in $M$, and $S$ to a greater extent.

It is only the second factor whose loadings are high on $\mathrm{H}$ and $\mathrm{L}$ and low on $\mathrm{M}$. Obviously such factor must be a language factor involving rote vocabulary, word fluency etc. very similar to the verbal factor as suggested by Spearman and Jones. ${ }^{3}$ ) To some extent this factor runs through all the subjects except Mt. But its loading on $\mathrm{H}$ is more than on L, contrary to the popular belief. In the study of Holzinger and Swinefold3), similar results have been obtained. ( $V$ factor loading on $\mathrm{H}$ is .416 and on $\mathrm{L}$ is .302). As has been pointed out ${ }^{1}$ ) the explanation of this apparent anomaly lies in our system of education. Success in $\mathrm{H}$ requires remembering factual contents, mastery over words and fluent writing, whereas for 
success in language paper one has to "give references, explain meanings and expand ideas" which requires one's originality, observation and clear thinking. This is one of the reasons why first factor has a high loading on $\mathrm{L}$ (Table 6). Besides, certain portions of language paper contain grammar which require neither a lot of vocabulary nor word fluency. Thus $H$ the ability of writing fluently and language "requires ability to think, create requires only and write."

A rowwise analysis of Table 6 suggests interestings. $M$ and $S$ are more ' $g$ ' saturated subjects than others. But while a language factor plays a major role in $\mathrm{S}$, it has its influence on $M$. This is because in $S$ we have essay type examination. Considering the overall success of the students we find that all the three factors are running through $\mathrm{Ag}$, though relatively non-verbal and verbal intelligence have more influence than the language factor. For H language factor is most important and other factors have a minor role. But $\mathrm{L}$ is more ' $\mathrm{g}$ ' saturated subject than $\mathrm{H}$, as the first factor loading is high on it. Therefore the belief that the student good at $\mathrm{M}$ is poor in $\mathrm{L}$ may not be true. Though language factor is very important for success in $\mathrm{L}$, verbal intelligence has rather low loading on it. For Gk verbal intelligence has its least loading, whereas the other two factors iufluence success in this subject to a greater extent.

\section{Summary and Conclusion}

The study makes an attempt to see the influence of non-verbal intelligence measured by Raven's Progressive Matrices (1938) on the success in individual school subjects and overall success in examination; and to find out meaningful factors running through these school subjects. With this end in view, Progressive Matrices scores and average marks of three successive school examinations in Mathematics, Languag=, History, Science, General Knowledge, and Aggregate, obtained by a group of 100 students of the top matriculation class were intercorrelated. The table of intercorrelations was then factor-analyzed by the centroid method.

The results of the study suggests (a) that non-verbal intelligence plays a major role for success in all the subjects except in History. It is most important for success in Mathematics, Science, and Aggregate. (b) For success in History and Language, a language factor (vocabulary, word fluency etc.) $i$; necessary. It has least loading on Mathematics. (c) A third factor verbal intelligence also plays an important role for success in Mathematics and Science and for overall success. (d) Verbal intelligence plays a minor role for success in History, Language, ane General Knowledge.

\section{REFERENCES}

1. Dash, S. C. A factor analytical study of examination marks. $J$. of Educ. \& Psychol., 1957, 17 No. 2. Baroda, India.

2. Raven, J.C. Guide to using Progressive Matrices (1938). London: H.K. Lewis, 1958.

3. Spearman, C. and Jones, L.L.W. Human ability.
London: Macmillan, 1951.

4. Thomson, G. The factorial analysis of human ability. London: Univer. Press, 1951.

5. Vernon, P. The structure of hum $m$ abilities London: Methuen, 1951.

MS. received IX 29, 59.

Rabindranath Kanungo, Shri. (1935- ） 1953 B. A. Utkal Univ., 1955 M. A. Patna Univ., now working for Ph. D. thesis; lecturer, Dept. of Psychol., Ravenshaw College.

S. C. Dash, Shri. (1931- ） 1953 B.Sc. Utkal Univ., 1955 M. Ed. Patna Univ., now preparing for Ph. D. thesis: 1955-1958 lecturer in education. Ravenshaw College, 1958- R.N. Training College, Cuttack. 